\title{
Factors Affecting Psychosocial Problems on the College Students Who Experience Smartphone Addiction
}

\author{
Wiwik W ${ }^{1, *}$, Widiharti ${ }^{2}$ and Firman F $\mathrm{S}^{3}$ \\ ${ }^{1,2}$ Faculty of Medicine, Muhammadiyah University of Gresik, Indonesia \\ ${ }^{3}$ Health Academy Sumenep, Sumenep - Madura, Indonesia \\ Corresponding author's e-mail: wiwikwidiyawati@umg.ac.id
}

\begin{abstract}
The number of smartphone users worldwide is increasing. This number has been estimated to reach 3.3 billion people. With all the features that a smartphone has, it can be a double-edged sword. Excessive use of smartphone results in physical and psychological problems. This study aimed to identify psychosocial health problems that arise in adolescents who have problems using their smartphones. Method : The population in this study was 17 -year-old college students who have had a smartphone for $>2$ years and were willing to participate. Data collection was carried out online with a total of 101 respondents using the questionnaire Scale Shorth Version (SAS SV), Self-Consciousness Scale, Shyness scale. The analysis was done univariably and used the pathway analysis. Results : Shyness through smartphones among college students was influenced by the factors of the category of residence $(0.19)$ and the duration of smartphone usage $(0.65)$. Social anxiety in college students through smartphone addiction was influenced by the duration of smartphone usage (0.13). Conclusion : The college students who experience smartphone addiction were overshadowed by health problems in psychological aspects such as shyness and social anxiety, stress, sleep disorders, and decreased sleep quality. If left unchecked, the student learning process or the absorption of knowledge will not be optimal. Consequently, it will have an impact on student learning outcomes. The various preventive measures related to existing problems, especially to prevent the increasing condition of smartphone addiction are necessary.
\end{abstract}

Keywords : Smartphone Addiction, Shyness, Social Anxiety, Stress, Sleep Disorders, Sleep Quality

\section{INTRODUCTION}

A smartphone is one of the devices that is a musthave for humans at this time since it has many functions and is needed by humans as if it were a portable computer device due to its function that almost resembles a computer. (1). There are many functions of a smartphone, especially the type of smartphone which is very useful and supports human life, from cameras, multimedia, internet access, navigation, mobile games, and social media access. (2). Along with the increase in function, the number of smartphone users worldwide is increasing. This number has been estimated to reach 3.3 billion people who use a smartphone, of which, China is at the top rank with more than 550 million people (3).

With all the features that a smartphone has, it can be a double-edged sword. On the one hand, the smartphone with various functions can have a positive effect, conversely, it can also have a negative effect. One of the positive functions of using a smartphone is to easily help all human activities, improve communication, and other specific abilities (4). However, the smartphone usage can also cause several problems such as nomophobia or smartphone addiction, internet addiction, mobile gaming addiction, cyberbullying, and hacking of personal data when using a smartphone. (2). When someone begins to experience problems in smartphone usage, it will cause several problems from economic and social problems due to decreased productivity of work or school assignments, decreased social interaction, and disruption of other social activities. $(2,5,6)$. Also, other problems starting from the problems related to physical health such as decreases in visual acuity, pain in the shoulders and neck, brain disorders, and cancer $(7,8)$. Other health problems that often arise besides physical problems are mental health problems, such as anxiety, loneliness, shyness, withdrawal, stress, depression, insomnia. (8).

Adolescents are one of the population that is very vulnerable to the impact of health problems that may arise due to the problems on smartphone usage because they have the highest smartphone usage intensity compared to other age groups (9). Besides, adolescents also use the smartphone as a lifestyle and necessity because they grow at the same time with the smartpones and the digital world (2). If adolescents who experience mental health are not handled immediately, it will harm their future. Based on this condition, the researcher intended to identify any psychological and psychosocial health problems that may arise in adolescents who experience 
problems with smartphone usage and to analyze what factors cause these mental health problems.

\section{METHODS}

\subsection{Population}

The research population was the college students at the Muhammadiyah University of Gresik from all existing faculties. The inclusion criteria of the research population were at least 17 years old college students who have had a smartphone with an IOS or Android operating system for approximately two years, had internet access, and were willing to participate in the data collection process.

\subsection{Data Collection}

Data collection was carried out through online-based surveys using online forms made from google form. The data collection was done during October 2019 with a total of 101 people filled out the form.

\subsection{Variable Measurement}

The socio-demographic data of respondents were measured using a questionnaire that was independently compiled by the researcher which related to age, sex, educational background, the category of the residence, residence location, monthly salary, and occupation. The habit of daily smartphone usage was measured using a questionnaire that was compiled by the researcher. They include daily smartphone usage times, applications that were most frequently accessed, sleeping hours, morning wake-up times, operating systems used, and monthly costs related to the smartphone usage.

Disturbance in smartphone usage was measured using the Smartphone addiction Scale Shorth Version (SAS SV) for college students or adolescents compiled by (10). SAS SV consisted of 10 questions. Social anxiety was measured using the Self-Consciousness Scale questionnaire compiled by
Fenigsten, Scheier, and Buss in 1975. On this scale, the respondents were asked to answer 5 question items. Shyness was measured using the Shyness scale compiled by Cheek and Buss. Respondents were asked to answer or provide responses to 6 existing questions.

\subsection{Data Collection}

Data collection was done during March-May 2020 2019. The research sample came from Muhammadiyah University students who were willing to become respondents and filled out an online questionnaire form that had been distributed through access to social media and posters on campus.

\subsection{Data Analysis}

Univariable data analysis was carried out by displaying the frequency distribution of each variable to see the percentage and total magnitude of each variable. A path analysis was carried out between all the existing variables after the univariable analysis. Before the path analysis was analyzed, the data transformation was carried out using the Method of Successive Internal (MSI) method to change the data from a categorical scale to a numerical data scale.

\section{RESULTS}

Most of the respondents were $<21$ years old $(78.2 \%)$. There were $65.4 \%$ of respondents aged 21 who experienced smartphone addiction. There were $73.1 \%$ of female respondents and experienced smartphone addiction. Most of the respondents had a high school educational background with a specialization in Social Sciences major (59.4\%). There were $69.2 \%$ of respondents with a high school educational background with a specialization in Science major who experienced smartphone addiction.

TABLE 1. The Characteristics of Respondents and Bivariable Analysis Results

\begin{tabular}{|c|c|c|c|c|c|}
\hline \multirow{2}{*}{\multicolumn{2}{|c|}{ Variable }} & \multicolumn{4}{|c|}{ Smartphone Addiction } \\
\hline & & $\mathrm{N}$ & $\%$ & $\mathrm{n}$ & $\%$ \\
\hline \multirow[t]{2}{*}{ Age } & $>21$ & 17 & 65.4 & 62 & 82.7 \\
\hline & $<=21$ & 9 & 40.9 & 13 & 17.3 \\
\hline \multirow[t]{2}{*}{ Sex } & Male & 7 & 26.9 & 28 & 37.3 \\
\hline & Female & 19 & 73.1 & 47 & 71.2 \\
\hline \multirow[t]{3}{*}{ Educational Background } & SHS (Senior High School) - Science Major & 7 & 26.9 & 19 & 25.3 \\
\hline & SHS (Senior High School - Social Science Major) & 18 & 69.2 & 42 & 56 \\
\hline & Vocational High School & 1 & 3.8 & 14 & 18.7 \\
\hline \multirow{2}{*}{$\begin{array}{l}\text { The Category of } \\
\text { Residence }\end{array}$} & Live with parents & 15 & 57.7 & 30 & 40 \\
\hline & Live separately with parents & 11 & 42.3 & 45 & 60 \\
\hline \multirow[t]{2}{*}{ Location } & Rural & 15 & 57.7 & 42 & 56 \\
\hline & Urban & 11 & 42.3 & 33 & 44 \\
\hline Occupation & Unemployed & 24 & 92.3 & 65 & 86.6 \\
\hline
\end{tabular}




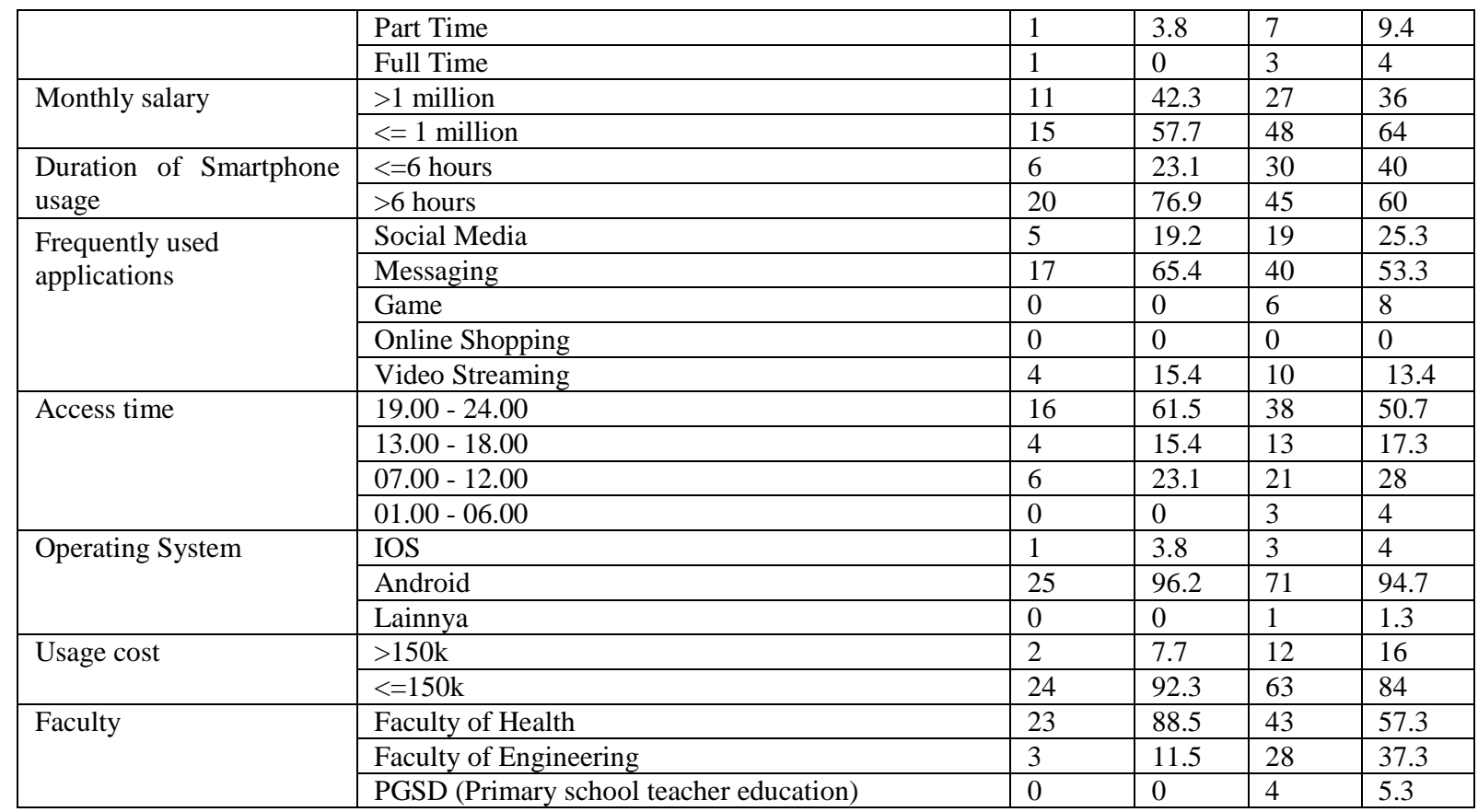

Most of the respondents used their smartphones to access applications with the type of messaging (56.4\%) such as WhatsApp, telegram, line, etc. There were $61.5 \%$ of respondents who most often used their smartphone at $19.00-24.00$ hours and experienced smartphone addiction. Most of the respondents have a smartphone with an Android- based operating system (95\%). There were $96.2 \%$ of respondents who have a smartphone with an Android operating system. They experienced smartphone addiction. Most of the respondents $(86.1 \%)$ spent monthly costs related to smartphone usage <= $150 \mathrm{k}, \%$. There were $92.3 \%$ of respondents who spend monthly costs $<=150 \mathrm{k}$ related to smartphone usage, they experienced smartphone addiction.

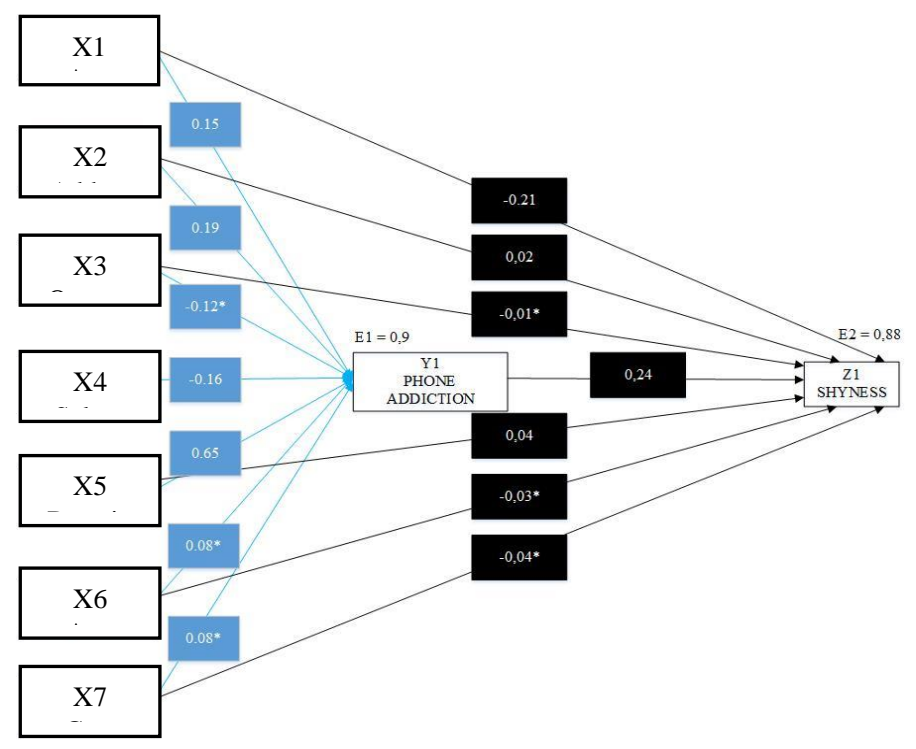

FIGURE 1. Pathway of Respondents' Shyness Condition

The analysis that has been done showed that the shyness that occurredd in respondents was directly influenced by the respondents' age $(0.21)$, the category of residence (0.02), the monthly salary $(0.04)$, and the duration of smartphone usage (0.04) which is done every day by respondents. Indirect 
effects related to the shyness on smartphone addiction on respondents, namely the place where the respondent lives (0.04) and the duration of smartphone usage $(0.15) . \mathrm{R}^{2}$ from the modeling formed was 0.12 or $12 \%$. This means that the shyness model that occurredd to respondents through the smartphone addiction that has been compiled can explain the shyness by $12 \%$, while $88 \%$ was influenced by other factors outside the established model. The results of the analysis showed that there were 2 variables related to the shyness of respondents through smartphone addiction, the structural model that was formed is:

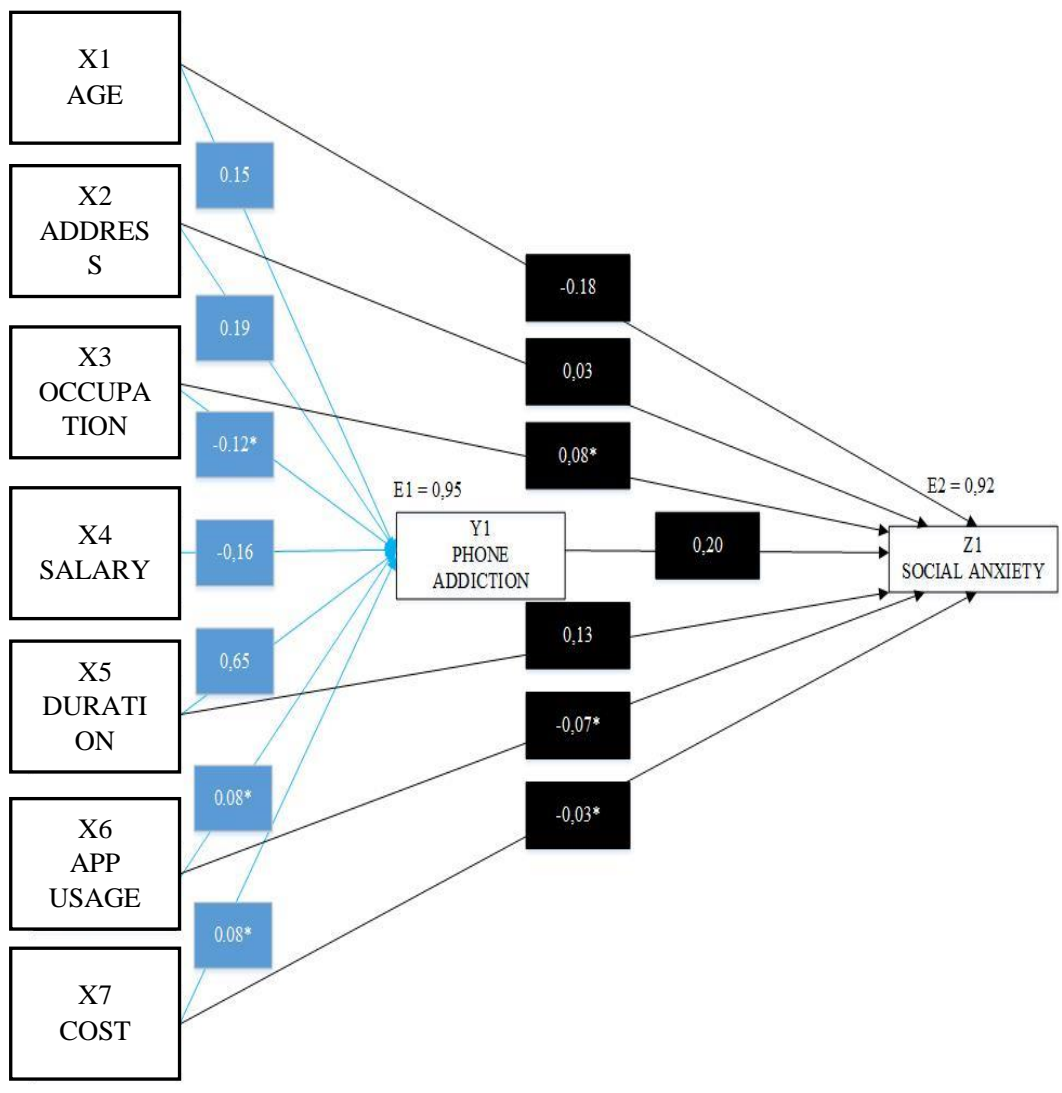

FIGURE 2. Pathway of Respondents' Social Anxiety Condition

The analysis that has been done showed that the social anxiety that occurred in respondents was directly influenced by the respondent's age (0.18), the category of residence $(0.03)$, and the duration of smartphone usage $(0.13)$ which is carried out every day by the respondents. The indirect effect related to social anxiety through smartphone addiction on respondents was the duration of smartphone usage (0.13). $\mathrm{R}^{2}$ from the modeling formed was 0.08 or $8 \%$. This means that the social anxiety model that occurred to respondents through the smartphone addiction that has been compiled can explain the social anxiety by $8 \%$, while $92 \%$ was influenced by other factors outside the established model. The results of the analysis showed that there was 1 variable that related to the social anxiety in respondents through smartphone addiction.

\section{DISCUSSION}

Shyness is a condition of restlessness, anxiety, no pleasant and obstructed, caused by the presence of other people. It can also be discomfort in the presence of others arising from a strong sense of self, in Mc Dougall's view, it causes by the existence of positive and negative feelings of self simultaneously. (Anggraini, 2015). The research results that have been conducted indicate that smartphone addiction is related to the shyness experienced by the respondents. The shyness of the respondent is also related to several factors that exist in the respondent 
such as the category of the respondent's residence, whether they live with their parents or lives separately in a boarding house. The duration of smartphone usage is also related to the shyness condition of the respondent. Similar research results are also found in a study conducted by Bian and Leung, (2015). A study conducted on university students in China shows that smartphone addiction is a predictor of the shyness that occurs in respondents. The college students who experience smartphone addiction tend to use a smartphone for a long time. One of the causes is the loneliness that occurred in respondents. If this condition is left unchecked, college students will experience shyness.

The excessive use of smartphones causes various health problems for its users. The preliminary research says that excessive use of smartphone causes physical and psychological disorders, especially in adolescents such as depression, anxiety, and sleep disorders (8). The high intensity of smartphone usage causes anxiety in a person. The higher the intensity of smartphone usage, the higher the anxiety that is felt, but the risk of anxiety decreases along with the decreasing intensity of smartphone usage (5). Excessive use of smartphones causes adolescent anxiety to be higher, vice versa, adolescents who have a low level of smartphone usage also have a low level of anxiety. People who experience smartphone addiction tend to have a high level of smartphone usage and tend to experience social isolation. The social isolation experienced by respondents causes them to experience social anxiety when they have to be in a social environment that has high interaction (5). The same statement is stated by Enez Darcin et al., (2016) that people who experience smartphone addiction tend to experience social anxiety. It is because they tend to experience a decrease in their relationship directly. People with smartphone addiction tend to socialize virtually through their smartphones, so they tend to find it difficult when they get direct physiological stimuli. Then they experience social anxiety. People who experience smartphone addiction tend to prefer social communication via social media or messaging applications, this is because they are not comfortable communicating face-to-face (13).

\section{CONCLUSION AND SUGGESTION}

The research results that have been conducted showed that the college students who experienced smartphone addiction were overshadowed by problems that were not only physical but also health problems in psychological aspects such as shyness, social anxiety. If left unchecked, the college students learning process or the absorption of knowledge will not be optimal. Consequently, it will have an impact on college student learning outcomes. If it is left in the long term, it will have an impact on adult life after studying at university. They will be adults with psychological problems. It is necessary to take various preventive measures related to existing problems, especially to prevent the increase in the condition of smartphone addiction which if left unchecked, will have an impact on further health problems both physically and psychologically.

\section{CONFLICT OF INTEREST}

The authors declare no conflict of interest

\section{ACKNOWLEDGMENTS}

The authors appreciate all those who helped complete this article.

\section{REFERENCES}

[1] Thomée S, Härenstam A, Hagberg M. Mobile phone use and stress, sleep disturbances, and symptoms of depression among young adults - a prospective cohort study. BMC Public Health. 2014; 11(66):1-11.

[2] Chen B, Liu F, Ding S, Ying X, Wang L, Wen Y. Gender differences in factors associated with smartphone addiction: A cross-sectional study among medical college students. BMC Psychiatry. 2017;17(1):1-9.

[3] Statista. Number of smartphone users worldwide 2014-2020. 2019 [cited 2019 Oct 18]. Available from: https://www.statista.com/statistics/330695/n umber-of-smartphone-users-worldwide/

[4] Chen L, Yan Z, Tang W, Yang F, Xie X, He J. Mobile phone addition levels and negative emotions among Chinese young adults: The mediating role of interpersonal problems. Computers in Human Behavior. 2016;55:856-66.

[5] Cheever NA, Rosen LD, Carrier LM, Chavez A. Computers in Human Behavior Out of sight is not out of mind: The impact of restricting wireless mobile device use on anxiety levels among low, moderate and high users. Computers In Human Behavior. 2014;37:290-7.

[6] Clayton RB, Leshner G, Almond A. The Extended iSelf: The Impact of iPhone Separation on Cognition, Emotion, and Physiology. Journal of Computer-Mediated Communication. 2015;12(5)1-17. 
[7] Kwon M, Lee J, Won W, Park J, Min J, Hahn $\mathrm{C}$, et al. Development and Validation of a Smartphone Addiction Scale ( SAS ). 2013;8(2).

[8] Demirci K, Akgönül M, Akpinar A. Relationship of smartphone use severity with sleep quality, depression, and anxiety in university students. Journal of Behavioral Addictions. 2015;4(2):85-92.

[9] Augner C, Hacker GW. Associations between problematic mobile phone use and psychological parameters in young adults. International Journal of Public Health. 2012;57(2):437-41.

[10] Kwon M, Kim DJ, Cho H, Yang S. The smartphone addiction scale: Development and validation of a short version for adolescents. PLoS ONE. 2013;8(12):1-7.

[11] Andreou E, Alexopoulos EC, Lionis C, Varvogli L, Gnardellis C, Chrousos GP, et al. Perceived Stress Scale: Reliability and validity study in Greece. International Journal of Environmental Research and Public Health. 2011;8(8):3287-98.

[12] Enez Darcin A, Kose S, Noyan CO, Nurmedov S, Yilmaz O, Dilbaz N. Smartphone addiction and its relationship with social anxiety and loneliness. Behaviour and Information Technology. 2016;35(7):520-5.

[13] Pierce T. "Social Anxiety and Technology: Face-to-Face Communication Versus Technological Communication among Teens." Computers in Human Behavior. 2009;25(1):1367-72.

[14] Zhang G, Yang X, Tu X, Ding N, Lau JTF. Prospective relationships between mobile phone dependence and mental health status among Chinese undergraduate students with college adjustment as a mediator. Journal of Affective Disorders. 2020;260:498-505. 